\title{
Interview with Varun Grover on "Business Processes, Information Technology and Its Evolution in the Digital Age"
}

\author{
Jan Mendling • Mieke Jans
}

Published online: 18 August 2021

(C) Springer Fachmedien Wiesbaden GmbH, ein Teil von Springer Nature 2021

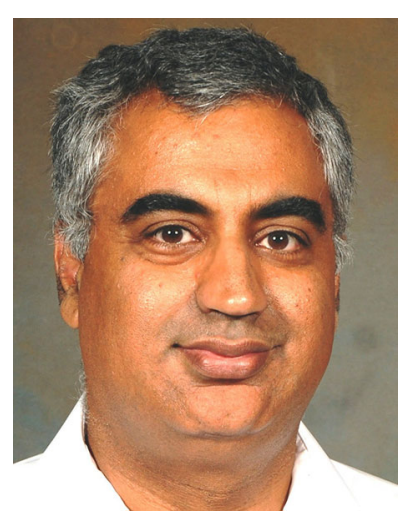

Varun Grover

Department of Information Systems

WCOB204

Walton College of Business

University of Arkansas

Fayetteville, AR 72701

USA

varungrover.com

Varun Grover is the George and Boyce Billingsley Chair and Distinguished Professor of IS at the Walton School of Business, University of Arkansas. Prior to this he was the William S. Lee (Duke Energy) Distinguished Professor of

\section{J. Mendling ( $\square)$}

Institut für Informatik, Humboldt-Universität zu Berlin, Unter den Linden 6, 10099 Berlin, Germany

e-mail: jan.mendling@hu-berlin.de

M. Jans

Universiteit Hasselt, Campus Diepenbeek, Agoralaan Gebouw D, 3590 Diepenbeek, Belgium
Information Systems at Clemson University. He has published extensively in the information systems field, with over 400 publications, 250 of which are in major refereed journals. Over ten recent articles have ranked him among the top four researchers globally based on number of publications in the top IS journals, as well as citation impact. Dr. Grover has an h-index of 96 and around 44, 000 citations in Google Scholar. Thompson Reuters recognized him as one of 100 Highly Cited Scholars globally in all Business disciplines. He is Senior Editor for MISQ Executive, Editor of the Journal of the Association for Information Systems Section on Path Breaking Research, and has served as Senior Editor for MIS Quarterly (2 terms), the Journal of the AIS ( 2 terms) and Database. Dr. Grover's current work focuses on the impacts of digitalization on individuals and organizations. He is a Fellow of the Association for Information Systems and is a recipient of numerous awards from USC, Clemson, AIS, Academy of Management, DSI, the OR Society, Anbar, PriceWaterhouse, among others for his research and teaching. Dr. Grover recently received the prestigious LEO Award for Lifetime Exceptional Achievement in Information Systems. He has had the privilege of being extensively involved with $\mathrm{PhD}$ students, serving as an advisor to over $45 \mathrm{PhD}$ students and as Co-Chair of numerous doctoral consortia at both the International Conference on Information Systems and Americas Conference on Information Systems. He has been invited to give numerous keynote addresses and talks at various institutions and forums around the world.

BISE: In your research, you have studied business processes and information systems since the 1990s. What was the reason that you came to investigate business processes at that time? 
Grover: In those days, the economy was down along with corporate profitability, and there was a buzz about a major overhaul needed in American corporations. While the term "process" had been prominent in concepts like TQM and Kaizan, it became a singular target of the problems with American companies in books by Hammer and Champy, as well as Davenport. What appealed to me about the concept was (a) it reflected a fundamental shift in the old organization, designed for command and control, to grow without going broke, in a stable noncompetitive environment, and the demands of the new environment with growing consumerism and hyper-competition. The transition made sense to me ... as many corporations fostered inertiadoing things because they had always been done that way without questioning whether the things they were doing were appropriate for the new environment. So, the higherlevel systems thinking aspect of this was logical, and the singular focus on business processes bounded the area, making it attractive to study; (b) I was always interested in the value proposition of information technology, and business process reengineering (BPR) gave me an intermediate concept that could mediate the relationship between IT investments and value. So, the profound involvement of IT in the process revolution made this even more interesting as there was a means of examining how to make IT investments more productive.

BISE: Your focus in the early 1990s is on the connection between business processes and strategy, change, implementation, and performance. What did you find out in your studies at that time?

Grover: Our program of work, in retrospect, proceeded quite systematically. Given the bandwagon effect of business process re-engineering in corporations in USA as well as the rest of the world, we had a rich repository of case studies, the vast majority of which were failed BPR initiatives. So, we started by inductively examining these cases and determining that BPR requires an organization wide integrated approach where strategy, information technology, and a facilitating innovative environment need to be aligned. We quickly realized that the quick fix "slash and burn" approach adopted by many companies was a recipe for disaster as it focused too much on cutting costs which meant people (downsizing) without consideration for how to manage such drastic change. We also found that in the more successful companies, acceptance and continuous assessment of process change is nurtured through an innovative environment. We then continued our work through a series of empirical studies that determined that cross-functional and cross-organizational projects benefit from an alignment of business strategy with IT, especially when the strategy focuses on low-cost orientation. Businesses that put their emphasis on processes within functions would not succeed in getting radical improvements in costs or productivity. We then turned our attention to specifically how IT changes processes and proposed that IT can reduce physical coupling and increase information coupling in processes. IT reduces physical coupling by changing serial processes involving many handoffs to parallel processes where all participants can see a common process through shared data and knowledge. IT increases information coupling by allowing collaboration across process participants, reducing uncertainty. These parallelcollaborative processes have implications for structure, management and people in progressive process-oriented enterprises.

Our further study led to diagnostics on process change in organization and concluded that these initiatives will only be successful if accompanied with the management of change, people and the project. IT competency is not instrumental for success; however, success requires concurrent changes in a breadth of environmental and managerial facilitators. Overuse of consultant-based methodologies to document existing processes does not yield commensurate results. Technology management must be part of a broader change program in order to have an effect. Most companies were focusing on IT or process optimization, and not enough on the human aspects of change management.

BISE: By the year 2000, research on business processesat least in information systems research-seems to have declined. What is your explanation for this?

Grover: I think there are many reasons for this. For one, as our own research indicates, the term was narrow, and increasingly required broader organizational change in order to be successful. So, while narrow technical work on process optimization and statistical control continued, the process aspects broadened into concepts like process management and business change/transformation. More importantly, new waves of initiatives claimed managerial attention. One was ERP systems, which promised turnkey IT solutions to tame jungles of functional systems. A lot of IS research focused on implementation of ERP systems and the process changes needed to preclude ERP failure. Also, e-Commerce consumed a major wave of attention as the belief (before the dot.com bust) was that the Internet changes everything, and processes could be subsumed effectively in B2C and B2B platforms. Finally, the management knowledge resources became a new source of competitive advantage and the early 2000s saw a wave of research dealing with knowledge management.

Of course, process reengineering is not dead. As we argue in our book (with Lynne Markus), if anything, processes and their improvement are more important than ever, because they are the essence of how work gets done. 
With these waves of change, the notion of business process is being layered and morphed with newer and richer concepts. This is exciting stuff! When we think of processes plus ERP systems, we open up provocative issues about the standardization or transfer of "best" business practices and about seamless system interfaces and modernized information architectures. When we think of processes layered with knowledge, we raise issues about how individuals, groups, and organizations can create, reuse and leverage tacit knowledge and about how firms can cooperate to create new knowledge products. When we think of service processes, we can explore service automation, consumer behavior, and changed information flows between organizations and their customers. Business process outsourcing raises issues of process standards and business networks. Innovation processes focus attention on exploration and discovery instead of exploitation and control. And, importantly, while process IS the missing link that explains the productivity paradox, when we think of today's digital initiatives, configuration allows processes are pivotal to value creation. Furthermore, the interactions among these ideas stimulate creative thinking about fundamental business challenges and opportunities. Whatever it is called today, business process transformation is richly layered with contemporary concepts that are germane to the modern enterprise and demand research attention.

BISE: Your research in the years 2000-2010 is less explicitly focusing on the term "business process", but giving more emphasis to knowledge, innovation, capabilities and value. How are business processes connected with these concepts?

Grover: It is true that along with the general decline of the term business process, our research also reduced its explicit focus on the term, and fragmented into areas tied to process change, but with the primary goal of examining the role and impact of IT initiatives. However, our study of process change in the 1990s was prominent in most of our work on the 2000s and continues to have a major influence on our thinking. For instance, we studied the importance of process change in realizing productivity value from a variety of different information technologies. We also studied ITbased market transformation and how buyer and supplier processes use IT to gain consumer surplus. Our study of knowledge management examined knowledge processes and their role in converting tacit knowledge into explicit knowledge repositories and ultimately into knowledge assets. We also studied how IT could create process and knowledge options that could lead to agile organizational responses in hypercompetitive environments. We also studied the role of inter-organizational systems on process efficiency. In general, while the vast majority of research during this period reflected the changing landscape of inter- organizational relationships and competitive advantage fostered by IT (Internet), processes attributes were still prominently reflected in most of this work.

BISE: By the year 2010, Business Process Management was increasingly establishing itself as a research area of its own, fostered by the success of the International Conference on Business Process Management and industry uptake of standards like BPMN or Web Service Orchestration. For ICIS 2010, you contributed to a panel discussion on "Business Process Management and the IS Field: Have we finally arrived or just missed the boat." How do you look at this panel discussion at hindsight?

Grover: I think we captured the definitional diversity of Business Process Management well in the panel. We identified the management methods (process improvement, reengineering, control \& monitoring), process methods (process modeling, simulation, optimization) and IT (ERP, service architecture, web services) as well as the focus of BPM in different disciplines (industrial engineering, operations research, operations management). What we underestimated is the pace of technological change, which had both a "magnifying effect" and a "configurational effect." IT rapidly took us to an environment of mobile apps, platforms and the ability to configure various digital objects into a compelling value proposition. So, documentation of "as is" processes and "to be" processes gave rise to the ability to configure processes (and corresponding software) and then magnify its effect via replication throughout the enterprise. So, our discussion was somewhat retrospective, missing the concepts of plug and play processes and their implications for organizational experimentation and flexibility. We also underestimated the inductive approach to reconstructing processes and diagnosing problems from digital data repositories. Clearly the availability of data and sophisticated analytical tools has changed the game.

BISE: After 2010, your research on the business value of IT eventually takes a focus on the concept of digital transformation, including big data and analytics. How does the process view fit into this research stream?

Grover: My recent work has focused more on the concept of "digital" and how it fundamentally differs from IT. The IT world that we have studied is replete with discrete boxes of hardware and software that we can study for adoption, implementation and use. The digital world builds on IT, but emphasizes digital objects (software, data, services) that can be configured into valuable resources for the consumer. Process aspects of this work are more implicit—but reflected in the technical process of digitization where analog representations are converted to bit strings, and the broader digitalization concept where the digital objects are 
used to transform organizational processes. Even in our discussion of big data, we argue that analytics can create value by improving the effectiveness, efficiency, and productivity of business processes. The three types of business process analysis are validation, verification, and performance, all requiring large volumes of process and event data. These analyses can explicitly benefit from process mining (e.g., inductive mining, event detection and analysis, bottleneck analysis, deviation analysis) can help identify the strengths and weaknesses of a business process. What used to be an intuitive decision can now be empirically supported with large-scale data analyses.

BISE: If you should give some final advice to junior information systems researchers, what would you recommend as interesting directions for research on business processes?

Grover: I think the biggest opportunities are in the digital space. There are so many digital transformations taking place, and yet there is $\mathrm{s}$ gap between these transformations and the rich repository of research done under the umbrella term business process management (BPM). We need to bridge this gap by improving our understanding of how BPM can play an enabling role in digital innovation, and how BPM can influence digital transformation. Concepts under traditional BPM labels like strategic alignment, governance, methods, culture and people, need to be further developed for the digital environment which demands new capabilities. I strongly believe that business processes are just as instrumental to success as they were in the 1990 s....we just need to invest in newer enlightened conceptualizations for the digital age.

\section{Further Readings (in chronological order)}

Hammer M, Champy J (1993) Reengineering the corporation: manifesto for business revolution. Harper Business

Davenport TH (1993) Process innovation: reengineering work through information technology. Harvard Business Press

Guha S, Grover V, Kettinger WJ, Teng JT (1997) Business process change and organizational performance: exploring an antecedent model. J Manag Inf Syst 14(1):119-154

Grover V, Davenport TH (2001) General perspectives on knowledge management: fostering a research agenda. J Manag Inf Syst 18(1):5-21

Bhatt GD, Grover V (2005) Types of information technology capabilities and their role in competitive advantage: an empirical study. J Manag Inf Syst 22(2):253-277

Kohli R, Grover V (2008) Business value of IT: an essay on expanding research directions to keep up with the times. J Assoc Inf Syst 9(1):1

Grover V, Markus ML (2008) Business process transformation. ME Sharpe

Radhakrishnan A, Zu X, Grover V (2008) A process-oriented perspective on differential business value creation by information technology: an empirical investigation. Omega 36(6):1105-1125

Grover V, Lyytinen K (2015) New state of play in IS research: the push to the edge. MIS Q 39(2):271-296

Lyytinen K, Grover V (2017) Management misinformation systems: a time to revisit. J Assoc Inf Syst 18(3):2

Grover V, Chiang RH, Liang TP, Zhang D (2018) Creating strategic business value from big data analytics: a research framework. J Manag Inf Syst 35(2):388-423

Piccoli G, Rodriguez J, Grover V (2020) Strategic initiatives and digital resources: construct definition and future research directions. In: Proceedings of the international conference for information systems, Hyderabad 